\title{
RECENT ADVANCES IN PROSTATE CANCER
}

Basic Science Discoveries and Clinical Advances 
This page intentionally left blank 


\section{RECENT ADVANCES IN PROSTATE CANCER}

Basic Science Discoveries and Clinical Advances

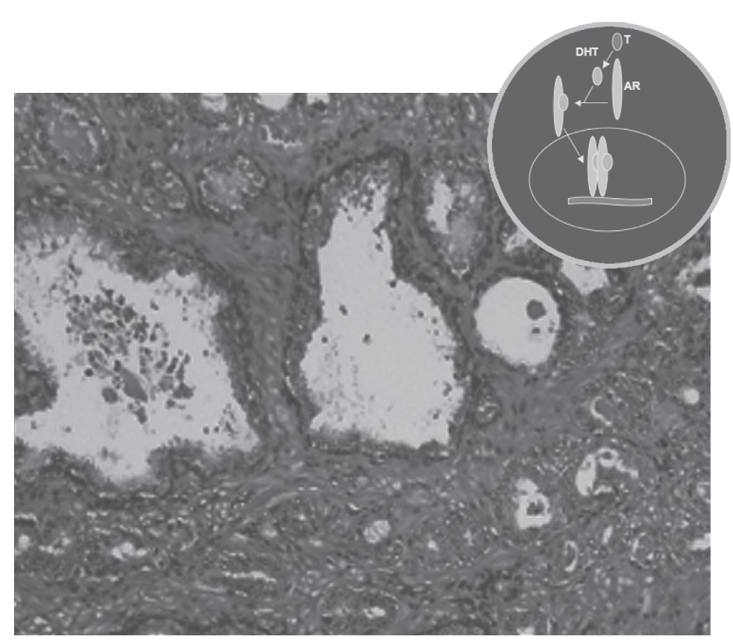

Editors

Donald J Tindall

Mayo Clinic College of Medicine, USA

\section{Peter T Scardino}

Memorial Sloan-Kettering Cancer Center, USA 
Published by

World Scientific Publishing Co. Pte. Ltd.

5 Toh Tuck Link, Singapore 596224

USA office: 27 Warren Street, Suite 401-402, Hackensack, NJ 07601

UK office: 57 Shelton Street, Covent Garden, London WC2H 9HE

\section{British Library Cataloguing-in-Publication Data}

A catalogue record for this book is available from the British Library.

\section{RECENT ADVANCES IN PROSTATE CANCER Basic Science Discoveries and Clinical Advances}

Copyright (C) 2011 by World Scientific Publishing Co. Pte. Ltd.

All rights reserved. This book, or parts thereof, may not be reproduced in any form or by any means, electronic or mechanical, including photocopying, recording or any information storage and retrieval system now known or to be invented, without written permission from the Publisher.

For photocopying of material in this volume, please pay a copying fee through the Copyright Clearance Center, Inc., 222 Rosewood Drive, Danvers, MA 01923, USA. In this case permission to photocopy is not required from the publisher.

ISBN-13 978-981-4329-45-3

ISBN-10 981-4329-45-2

Typeset by Stallion Press

Email: enquiries@stallionpress.com

Printed in Singapore. 


\section{CONTENTS}

Contributors $\quad$ xiii

Preface xxiii

Chapter 1 Pathology of Prostate 1

Lawrence True and Funda Vakar-Lopez

Introduction

Prostate Anatomy

Benign Prostatic Hypertrophy (BPH)

Inflammation

Pre-Neoplastic Lesions $\quad 6$

Prostate Carcinoma 9

$\begin{array}{ll}\text { Spindle Cell Lesions } & 17\end{array}$

Pathology of Non-Surgical Therapy 19

Recommendations for Pathology Reports 22

Tissue Biomarkers 26

$\begin{array}{ll}\text { Future Trends } & 28\end{array}$

Chapter 2 Genetic Basis for Prostate Cancer 39

Stacy Loeb and William B. Isaacs

Introduction

Family-Based Studies $\quad 40$

Genome-Wide Association Studies $\quad 43$

Future Directions $\quad 48$

Conclusions $\quad 49$ 
Chapter 3 Androgen Receptor Converts from a

Growth Suppressor in the Normal Prostate to an Oncogene in Prostate Cancer Donald J. Vander Griend and John T. Isaacs

Androgen Receptor Suppresses the Growth of Normal Prostate 54 Epithelial Cells

Androgen Receptor Functions as an Oncogene in Prostate

Cancer

Clinical Implications of AR Conversion from a Growth

Suppressor to an Oncogene

Loss of AR-Mediated Growth Suppression Without Gaining

Oncogenic Ability

Acknowledgments

Chapter 4 Etiology: Role of ETS Factor Gene Fusions Jianghua Wang and Michael Ittmann

Introduction

ETS Transcription Factor Gene Fusions in Prostate Cancer 68

Structure and Transcription of the TMPRSS2/ERG

Fusion Gene

Origin of the TMPRSS2/ERG Fusion Gene

Alternative Splicing of the TMPRSS2/ERG Fusion Transcript 71

Pathological Correlations

The ETS Transcription Factor Gene Family

Biological Activities of the ERG and T/E Fusion

75

Gene Protein

Association of T/E Fusion Gene Expression with Global

Gene Expression and Copy Number Alterations in

Prostate Cancer

Genetics of TMPRSS2/ERG Prostate Cancer

Clinical Implications of the TMPRSS2/ERG Fusion Gene 
Chapter 5 Etiology of Prostate Cancer: Role of Inflammation

William G. Nelson, Angelo M. DeMarzo

and Srinivasan Yegnasubramanian

$\begin{array}{ll}\text { Introduction } & 97\end{array}$

Inflammation in the Human Prostate and Prostate Cancer 98

Sex Steroid Hormones and Inflammation in the Prostate 102

Infections and Inflammation in the Prostate 105

Inflammation and Inherited Susceptibility to Prostate Cancer 107

The Diet and Inflammation in the Prostate 109

Inflammation and the Molecular Pathogenesis 111 of Prostate Cancer

Is Prostate Inflammation the Unifying Mechanism 114 for Prostatic Carcinogenesis?

Summary and Conclusions

116

Chapter 6 Tumor Biology

133

Elisa Benedettini, Kathryn L. Penney, Michelangelo Fiorentino and Massimo Loda

Introduction

Epidemiology and Risk Stratification

Germline Genetic Variations and PCa

Somatic Events

Altered Pathways in PCa

Lipogenesis and Metabolic Alterations

Mouse Models of PCa

Tissue Biomarkers

Conclusions

Chapter 7 The Androgen Receptor

Kaustubh Datta, Kimberly B. Dablman,

Charles L. Sawyers and Donald J. Tindall

Introduction 
AR Function in Androgen-Dependent Prostate Cancer 173

AR in Castration-Resistant Prostate Cancer 178

$\begin{array}{ll}\text { Summary } & 186\end{array}$

Chapter 8 Intracrine Synthesis of Androgens by 193 Prostate Cancer in Response to Androgen Deprivation Therapy

James L. Mobler, Mark A. Titus, Alejandro S. Godoy, Daizo Oka and Peter S. Nelson

Introduction

Androgen Receptor Reactivation in CR-CaP

CR-CaP has Tissue Levels of Testicular Androgens Sufficient for Androgen Receptor Activation

Provision of Androgen Receptor Ligands During Androgen 200

Deprivation Therapy by Intracrine Synthesis of

Testicular Androgens

Clinical Relevance of Hypersensitization of AR

and Altered Androgen Metabolism During Androgen

Deprivation Therapy

CYP17Al Inhibitors

5-Alpha-Reductase Inhibitors

Conclusions and Future Directions $\quad 207$

Acknowledgments

Chapter 9 Genetically Engineered Mouse Models Michael M. Shen and Cory Abate-Shen

Introduction

Technologies for Creating Gem Models

Viral Oncogene-Driven Models

Protooncogene-Driven Models

The Tumor Suppressor Models 
Models with Aberrant Growth Factor Signaling

Remarks and Perspectives

Chapter 10 Detection of Prostate Cancer: PSA Amit Gupta, Hans Lilja and Fritz H. Schroeder

Introduction

Factors that Influence PSA Levels

Improving PSA Test Characteristics

Long-Term Prostate Cancer Prediction

How to Use PSA as an Indicator for Biopsy

Screening for Prostate Cancer, the Randomized Trials

Guidelines on Early Detection of Prostate Cancer with PSA

Acknowledgments

\section{Chapter 11 Imaging of Prostate Cancer}

Esther Mena, Baris Turkbey, Karen Kurdziel and Peter L. Choyke

Introduction

Convectional Imaging Techniques

Functional MR Imaging

Nuclear Medicine Techniques

Conclusion and Summary

Chapter 12 Role of Nomograms in the Management of Prostate Cancer Andrew J. Stephenson, Carvell T. Nguyen and Michael W. Kattan

Introduction

Rationale for Formalized Prediction of Clinical Outcomes $\quad 377$

The Evolution of Prostate Cancer Prediction Models 378

The Superiority of Nomograms in Outcomes Prediction 380

Building a High Quality Nomogram 384

Clinical States of Prostate Cancer and Their 386

Corresponding Nomograms 
Clinically Localized Disease $\quad 388$

Nomograms for Other Clinical States 399

Limitations of Nomograms 401

Future Directions $\quad 404$

$\begin{array}{ll}\text { Conclusions } & 405\end{array}$

Chapter 13 Decision Points and Results of Radiotherapy 411 by Prostate Cancer Risk Group

Dayssy Alexandra Diaz and Alan Pollack

Introduction

Low Risk Prostate Cancer $\quad 412$

$\begin{array}{ll}\text { Brachytherapy } & 416\end{array}$

Intermediate Risk Prostate Cancer $\quad 423$

High Risk Prostate Cancer $\quad 431$

Postoperative Radiotherapy 438

Chapter 14 Treatment of Prostate Cancer: Surgery 451

Vincent P. Laudone, Bertrand D. Guillonneau, Karim A. Touijer and James A. Eastham

Introduction

Staging of Prostate Cancer $\quad 461$

Preoperative Assessment $\quad 465$

Technical Aspects of Radical Prostatectomy 468

Techniques to Improve Outcomes after Radical Prostatectomy $\quad 470$

Indications for Radiotherapy after RP: Adjuvant or 507

Salvage Radiotherapy?

The Natural History of a Rising PSA after RP

Chapter 15 Treatment of Prostate Cancer - Hormonal 519 Therapy

Aymen Elfiky and Philip Kantoff

Principles of Hormone Therapy - The Androgen Receptor 519 Approaches to Initial Androgen Deprivation 521

Clinical Scenarios Requiring Use of Hormone Therapy 526 
Controversies in the Use of Hormone Therapy 539

New Approaches to Hormone Therapy 546

Chapter 16 Chemotherapy for Castration-Resistant 559 Prostate Cancer

Gopa Iyer, Howard I. Scher and David B. Solit

Introduction

Prostate Cancer Clinical States and Clinical Trial Methodology 560

Cytotoxic Chemotherapy for Castration

Resistant-Prostate Cancer

Studies of Docetaxel-Based Combination Regimens $\quad 575$

Other Cytotoxic Agents $\quad 594$

Novel Targeted Approaches $\quad 602$

Chapter 17 Novel Therapeutic Approaches to Advanced 617 Prostate Cancer

Matthew K. Tollefson and Eugene D. Kwon

Introduction

Secondary Hormonal Manipulation $\quad 618$

$\begin{array}{ll}\text { Immunotherapy } & 620\end{array}$

Cytotoxic Chemotherapy $\quad 626$

Antiproliferative Agents $\quad 630$

Angiogenesis Inhibitors $\quad 631$

Mammalian Target of Rapamycin $\quad 635$

Nucleoside-Based Targeted Therapy 636

Plea for a Multimodal Approach $\quad 639$

$\begin{array}{ll}\text { Conclusion } & 639\end{array}$

Chapter 18 Prevention of Prostate Cancer: A Focus on 647 Completed Clinical Trials and a Vision of the Future

John P. Fitzgerald, Melissa Talbert

and Ian Thompson

Introduction

Rationale for Prevention 
Chemoprevention with Selenium and Vitamin E:

650

The Selenium and Vitamin E Cancer Prevention Trial (SELECT)

Chemoprevention with Finasteride: The Prostate Cancer

Prevention Trial

Conclusions Regarding Finasteride and Prevention of

Prostate Cancer

Chemoprevention of Prostate Cancer with Dutasteride: 658 The Reduce Trial

Future Directions in Prostate Cancer Chemoprevention 659

Statins

660

Dietary Fat

661

Other Strategies

662

Conclusions

663

Index 


\section{CONTRIBUTORS}

\section{Cory Abate-Shen, PhD}

Departments of Urology and Pathology and Cell Biology

Herbert Irving Comprehensive Cancer Center

Columbia University Medical Center

New York, NY 10032, USA

Elisa Benedettini, PhD

Department of Medical Oncology

Dana-Farber Cancer Institute

Harvard Medical School

Boston, MA 02115, USA

Peter L. Choyke, MD

Molecular Imaging Program

National Cancer Institute

National Institutes of Health

Bethesda, MD 20892, USA

Kimberly B. Dahlman, PhD

Memorial Sloan-Kettering Cancer Center

New York City, NY 10065, USA 


\section{Kaustubh Datta, PhD}

Assistant Professor

Departments of Urology

Biochemistry and Molecular Biology

Mayo Clinic College of Medicine

Rochester, MN 55905, USA

\section{Angelo M. DeMarzo, MD, PhD}

Department of Pathology

Johns Hopkins University School of Medicine

Baltimore, MD 21231, USA

\section{Dayssy Alexandra Diaz, MD}

Department of Radiation Oncology

University of Miami/Jackson Memorial Hospital

Sylvester Comprehensive Cancer Center

Miami, FL 33136, USA

\section{James A. Eastham, MD, FACS}

Chief, Urology Service

Florence and Theodore Baumritter/

Enid Ancell Chair of Urologic Oncology Department of Surgery Assistant Attending Surgeon

Division of Urology

Memorial Sloan Kettering Cancer Center

New York, NY 10065, USA

\section{Aymen Elfiky, MD, MA, MPH}

Dana-Farber Cancer Institute/

Brigham and Women's Hospital

Harvard Medical School

Boston, MA 02115, USA

\section{Michelangelo Fiorentino, $\mathrm{MD}, \mathrm{PhD}$}

Center for Oncologic Molecular Pathology

Dana Farber Cancer Institute

Boston, MA 02115, USA 
John P. Fitzgerald, MD, MA

Clinical Instructor

Department of Urology

University of Texas Health Science Center at San Antonio

San Antonio, TX 78229, USA

Alejandro S. Godoy, PhD

Department of Urology

Roswell Park Cancer Institute

Buffalo, NY 14263, USA

Bertrand D. Guillonneau, MD

Head, Department of Urology

GH Diaconesses - Croix St. Simon

75012 Paris, France

Amit Gupta, MD, MPH

Department of Surgery (Urology)

Memorial Sloan-Kettering Cancer Center

New York City, NY 10065, USA

\section{John T. Isaacs, $\mathrm{PhD}$}

Chemical Therapeutics Program and

Professor of Oncology and Urology

The Sidney Kimmel Comprehensive Cancer Center at Johns Hopkins

Professor in the Cellular and Molecular Medicine Graduate Program

The Johns Hopkins School of Medicine

Professor of Chemical and Biomolecular Engineering

The Whiting School of Engineering

The Johns Hopkins University

Baltimore, MD 21287, USA

William B. Isaacs, PhD

Professor

Urology and Oncology 
Johns Hopkins University

School of Medicine

Johns Hopkins Hospital

Baltimore, MD 21287, USA

\section{Michael Ittmann, $\mathrm{MD}, \mathrm{PhD}$}

Department of Pathology and Immunology

Baylor College of Medicine and

Michael E. DeBakey Department of Veterans

Affairs Medical Center

Houston, TX 77030, USA

\section{Gopa Iyer, MD}

Genitourinary Oncology Service

Department of Medicine

Memorial Sloan-Kettering Cancer Center

New York, NY 10065, USA

\section{Philip Kantoff, MD}

Chief Clinical Research Officer

Chief, Division of Solid Tumor Oncology

Director of the Lank Center for Genitourinary Oncology

Dana-Farber Cancer Institute/Brigham and Women's Hospital

Professor of Medicine

Harvard Medical School

Boston, MA 02115, USA

\section{Michael W. Kattan, PhD}

Professor of Medicine, Epidemiology and Biostatistics

Cleveland Clinic Lerner College of Medicine

of Case Western Reserve University

Chairman, Department of Quantitative

Health Sciences, Cleveland Clinic

Cleveland, OH 44195, USA 
Karen Kurdziel, MD

Molecular Imaging Program

National Cancer Institute

National Institutes of Health

Bethesda, MD 20892, USA

Eugene D. Kwon, MD

Professor of Immunology and Urology

Mayo Clinic

Rochester, MN 55905, USA

Vincent P. Laudone, MD

Associate Attending Surgeon

Division of Urology

Co-Director, Robotic Surgery Program

Department of Surgery

Memorial Sloan Kettering Cancer Center

New York, NY 10065, USA

Hans Lilja, MD, PhD

Departments of Clinical Laboratories

Surgery (Urology), and Medicine (GU-Oncology)

Memorial Sloan-Kettering Cancer Center

New York City, NY 10065, USA

Department of Laboratory Medicine, Malmö

Division of Clinical Chemistry

Lund University

University Hospital UMAS

20502 Malmö, Sweden

\section{Massimo Loda, MD}

Department of Pathology

Dana Farber Cancer Institute

Brigham and Women's Hospital, Broad Institute Professor of Pathology, Harvard Medical School Boston, MA 02115, USA 
Stacy Loeb, MD

Brady Urological Institute

Johns Hopkins Medical Institutions

Baltimore, MD 21287, USA

\section{Wallace L. McKeehan, PhD}

Center for Cancer and Stem Cell Biology

Institute of Biosciences and Technology

Texas A\&M Health Science Center

Houston, TX 77030, USA

\section{Esther Mena, MD}

Molecular Imaging Program

National Cancer Institute

National Institutes of Health

Bethesda, MD 20892, USA

\section{James L. Mohler, MD}

Associate Director and Senior Vice President for Translational Research

Chair, Department of Urology

Roswell Park Cancer Institute

Buffalo, NY 14263, USA

School of Medicine and Biomedical Sciences

State University of New York at Buffalo

Lineberger Comprehensive Cancer Center

University of North Carolina at Chapel Hill

\section{Peter S. Nelson, MD}

Human Biology Division

Fred Hutchinson Cancer Research Center

Seattle, WA 98109, USA

\section{William G. Nelson, MD, PhD}

Sidney Kimmel Comprehensive Cancer Center Baltimore, MD 21231, USA 


\title{
Carvell T. Nguyen, MD, PhD
}

Fellow, Center for Urologic Oncology

Glickman Urological and Kidney Institute

Cleveland Clinic

Cleveland, OH 44195, USA

\section{Daizo Oka, MD, PhD}

Department of Urology

Osaka University Graduate School of Medicine

Osaka 565-0871, Japan

\section{Kathryn L. Penney, ScD}

Department of Epidemiology

Harvard School of Public Health

Channing Laboratory

Department of Medicine

Brigham and Women's Hospital

Boston, MA 02115, USA

\author{
Alan Pollack, MD, PhD \\ Department of Radiation Oncology \\ University of Miami \\ Sylvester Comprehensive Cancer Center \\ Miami, FL 33136, USA
}

\section{Charles L. Sawyers, MD}

Chair, Human Oncology and Pathogenesis Program

Marie-Josee and Henry R. Kravis Chair

Memorial Sloan-Kettering Cancer Center

New York City, NY 10065, USA

\section{Howard I. Scher, MD}

Chief, Genitourinary Oncology Service

D. Wayne Calloway Chair in Urologic Oncology

Department of Medicine 
Sidney Kimmel Center for Prostate and Urologic Cancers

Memorial Sloan-Kettering Cancer Center

New York, NY 10065, USA

\section{Fritz H. Schroeder, MD, PhD}

Department of Urology

Erasmus University Medical Centre

Erasmus University Rotterdam

3015 CE, Rotterdam, The Netherlands

\section{Michael M. Shen, PhD}

Department of Medicine and Genetics and Development

Herbert Irving Comprehensive Cancer Center

Columbia University Medical Center

New York, NY 10032, USA

\section{David B. Solit, MD}

Human Oncology and Pathogenesis Program

Genitourinary Oncology Service

Department of Medicine

Memorial Sloan-Kettering Cancer Center

New York, NY 10065, USA

\section{Andrew J. Stephenson, MD, FACS, FRCS(C)}

Associate Professor of Surgery

Case Western Reserve University School of Medicine

Director, Center for Urologic Oncology

Glickman Urological and Kidney Institute

Cleveland Clinic

Cleveland, OH 44195, USA

\section{Melissa Talbert, MD}

Department of Urology

University of Texas Health Science Center at San Antonio San Antonio, TX 78229, USA 


\section{Ian Thompson, MD}

Director, Cancer Therapy and Research Center

Professor, Department of Urology

University of Texas Health Science Center at San Antonio

San Antonio, TX 78229, USA

\section{Donald J. Tindall, PhD}

Professor, Director and Vice Chair of Urologic Research

Carl Rosen Professorship in Urology

Departments of Urology

Biochemistry and Molecular Biology

Mayo Clinic College of Medicine

Rochester, MN 55905, USA

Mark A. Titus, PhD

Department of Urology

Roswell Park Cancer Institute

Buffalo, NY 14263, USA

\section{Matthew K. Tollefson, MD}

Assistant Professor of Urology

Mayo Clinic

Rochester, MN 55905, USA

\section{Karim A. Touijer, MD}

Assistant Attending Surgeon

Division of Urology

Memorial Sloan Kettering Cancer Center

New York, NY 10065, USA

\section{Lawrence True, MD}

Professor of Pathology

Department of Pathology

University of Washington

Seattle, WA 98195, USA 
Baris Turkbey, MD

Molecular Imaging Program

National Cancer Institute

National Institutes of Health

Bethesda, MD 20892, USA

\section{Funda Vakar-Lopez, MD}

Assistant Professor of Pathology

Department of Pathology

University of Washington

Seattle, WA 98195, USA

\section{Donald J. Vander Griend, PhD}

Assistant Professor

Department of Surgery

Section of Urology

The University of Chicago

Chicago, IL 60637, USA

\section{Fen Wang, PhD}

Center for Cancer and Stem Cell Biology

Institute of Biosciences and Technology

Texas A\&M Health Science Center

Houston, TX 77030, USA

\section{Jianghua Wang, MD}

Department of Pathology and Immunology

Baylor College of Medicine and

Michael E. DeBakey Department of Veterans

Affairs Medical Center

Houston, TX 77030, USA

Srinivasan Yegnasubramanian, $\mathrm{MD}, \mathrm{PhD}$

Sidney Kimmel Comprehensive Cancer Center

Baltimore, MD 21231, USA 


\section{PREFACE}

Prostate Cancer is the most common internal cancer in men in the United States and the second leading cause of cancer-related death in men. Prostate cancer incidence has been declining in the United States over the past decade, probably because intense screening with prostate-specific antigen (PSA) and aggressive biopsy techniques have removed many of the prevalent cancers from the population. Mortality rates from prostate cancer have been declining for more than two decades, and age-adjusted mortality rates are $45 \%$ below their peak in 1992 , most likely as a result of early detection and effective treatment of potentially lethal cancers. The decline in mortality has come at the cost, to some degree, of excess treatment of many indolent cancers that posed little risk to life or health. Despite two multinational screening trials to determine the benefits of widespread PSA testing, the subject remains fraught with controversy. Active surveillance is gaining acceptance as a conservative management strategy in men with low risk cancers, although we are not sure exactly who should qualify for this "watchful waiting" approach or how best to determine when to intervene later if the tumor progresses. Chemoprevention of prostate cancer with 5-alpha reductase inhibitors is a promising way to reduce the incidence of cancer, but the U.S. Food and Drug Administration recently declined to approve these drugs because of concern that they may slightly increase the risk that a man will develop a high grade cancer - a controversial judgment that will require intense investigation to substantiate or refute. 
A central factor in prostate cancer initiation, maintenance and progression is the androgen signaling pathway. Androgens play important roles in the development of fusion oncogenes that are important in the initiation of prostate cancer. Androgens also stimulate pathways that are critical in proliferation of cells during the maintenance and progression of prostate cancer. Even after androgen deprivation therapy, prostate cells initiate mechanisms that preserve the activity of the androgen receptor. Other signaling pathways that regulate inflammation, cell cycle, cell survival genomic instability and cell killing play key roles in prostate cancer initiation, maintenance and progression. A critical need for the clinical management of prostate cancer is an ability to distinguish between indolent and aggressive disease beyond Gleason grading. DNA arrays have begun to define genes that are associated with aggressive and non-aggressive tumors. The future looks promising for the validation of such biomarkers that may be useful for prognosis and for directing therapy.

Improved treatment of prostate cancer has benefitted from a better understanding of the cellular mechanisms that contribute to the disease as well as the molecular mechanisms through which drugs act on tumors. In the past five years clinical trials have established the effectiveness of a number of new drugs for advanced prostate cancer, including docetaxel, sipuleucel, carbazitaxel, and abiraterone, which promise to improve the survival of these patients. Docetaxel and carbazitaxel destabilize microtubules, resulting in cell death. Sipuleucel appears to enhance the immune response to prostate cancer.

Abiraterone blocks androgen synthesis not only in the adrenal gland, but in the cancer cells themselves, which seem to develop autocrine mechanisms to synthesize androgens in response to long term androgen deprivation. In addition to advanced surgical and radiation techniques, these drugs will contribute profoundly to improved treatment for prostate cancer and longer survival. Nonetheless, every treatment comes with a potential for adverse side effects.

This book will summarize our current knowledge of prostate cancer, highlighting the key recent advances. It covers our state-ofthe-art understanding of risk factors, prevention, detection, prognosis and treatment of this disease. By including both basic scientists and 
clinicians as authors, the book will identify the most important recent basic science findings that are being translated into clinical practice, as well as the most promising areas of research that could have the greatest impact on clinical practice in the future. Our understanding of prostate cancer is rapidly evolving. This book should serve as a valuable summary of the current status of the field for the laboratory scientists, the clinician caring for the patient and for those in training who are dedicating their professional efforts to help reduce the burden of suffering and death from this all too common disease.

Donald J. Tindall, PhD Mayo Clinic College of Medicine Peter T. Scardino, MD, FACS Memorial Sloan-Kettering Cancer Center 